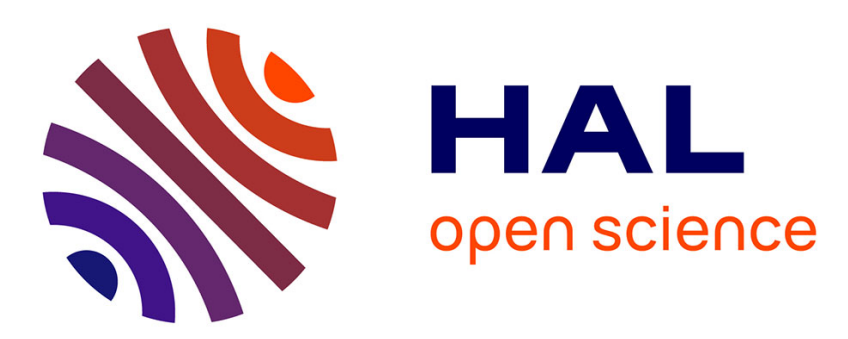

\title{
Digital Parrhesia as a Counterweight to Astroturfing
}

François Allard-Huver, Nicholas Gilewicz

\section{To cite this version:}

François Allard-Huver, Nicholas Gilewicz. Digital Parrhesia as a Counterweight to Astroturfing. Online Credibility and Digital Ethos: Evaluating Computer-Mediated Communication, IGI Global, pp.215-227, 2013, 10.4018/978-1-4666-2663-8.ch012 . hal-02092105

\section{HAL Id: hal-02092105 \\ https://hal.science/hal-02092105}

Submitted on 7 Apr 2019

HAL is a multi-disciplinary open access archive for the deposit and dissemination of scientific research documents, whether they are published or not. The documents may come from teaching and research institutions in France or abroad, or from public or private research centers.
L'archive ouverte pluridisciplinaire HAL, est destinée au dépôt et à la diffusion de documents scientifiques de niveau recherche, publiés ou non, émanant des établissements d'enseignement et de recherche français ou étrangers, des laboratoires publics ou privés. 


\title{
Digital parrhesia as a counterweight to astroturfing
}

\author{
François Allard-Huver \\ CELSA Graduate School of Communication, Paris-Sorbonne University, Paris IV, \\ France \\ Nicholas Gilewicz \\ Annenberg School for Communication, University of Pennsylvania, USA
}

\begin{abstract}
Astroturfing — fake grassroots communications about an issue of public interest-is further problematized in digital space. Because digitally mediated communications easily accommodate pseudonymous and anonymous speech, digital ethos depends on a finding a proper balance between the ability to create pseudonymous or anonymous online presences, and the public need for transparency in public speech. Analyzing such content requires analysis of media forms and analysis of the honesty of speakers themselves. This chapter applies Michel Foucault's articulation of parrhesia - the ability to speak freely and the concomitant public duties it requires of speakers - to digital communications. It first theorizes digital parrhesia, then outlines a techno-semiotic methodological approach with which researchers - and the public — can consider online advocacy speech. The chapter then analyzes two very different instances of astroturfing using the technosemiotic method in order to demonstrate the generalizability of the theory of digital parresia, and the utility of the techno-semiotic approach.
\end{abstract}

\section{INTRODUCTION}

Astroturfing — fake grassroots campaigns about matters of public interest—presents a particular problem to researchers, particularly to those interested in studying the content of advocacy speech. Specifically, the content may be true, and even compelling, but if the honesty of the speaker is questionable, that truth may be a house of cards.

In this chapter, we expand Pramad K. Nayar's application of parrhesia to digital space (2010). Relying, as did Nayar, on Foucault's articulation of this ancient Greek concept (Foucault, 2001), this chapter derives a model for analyzing the credibility of digital advocacy speech, and thus a model for truth-telling in the digital public sphere.

Parrhesia, or the ability to speak freely, implies three public duties for speakers: to speak the truth, to sincerely believe that truth, and to honestly represent themselves when speaking. Astroturfing, which conceals identities in order to reduce the risks of speaking truth to power-or to the public - always fails the latter duty. 
In networked space, however, pseudonymous and anonymous speech can work both democratically and propagandistically. This chapter proposes that digital parrhesia helps evaluate astroturfing and helps understand why such evaluation matters. By using digital parrhesia to analyze astroturfing online, this chapter's analytic model aims to contribute to the preservation - and maybe the revivification of - a culture of truth-telling.

\section{Background: Astroturfing is not for Free}

On May 16, 2010, the French popular science show $E=M 6$ featured a story about "triple play boxes." A new communication service in France, the boxes allowed users to access the Internet, television, and telephone services at the same time and through the same provider. $E=M 6$ achieved its popularity by mixing the points of view of scientists and technicians with discussion of consumer uses and needs - thus, the boxes were wellsuited for a story on this program. Every broadcast of $E=M 6$-named for M6, its channel - follows a format similar to this episode, where the broadcast first explained the science behind the broadcast in terms fit for a general audience, and second explored the contextual uses of the boxes.

This episode featured a happy French family, a couple with two children, who discovered the features of the box. When the mother called the children for dinner during their favorite cartoon, the box allowed them to pause the program and store it on the box's hard drive. When the family took a walk, and worried they would miss an evening show, the father programmed the box using his smartphone. In these ways, the family met their entertainment needs thanks to the little box. But shortly after the episode aired, fans and customers, re-watching the episode on M6's Web site, noticed that the box something called a Freebox, available exclusively from the Internet provider Free. Fans began to discuss the show and the Web site Freenews.fr, created by an association of Free customers, reported that the family was, in fact, a fake: the "father" was Free's marketing director, and the "mother" was Free's press secretary (Freenews, 2011a; Freenews, 2011b).

Other Web sites and radio and television news reported the dishonesty; ultimately, the French broadcasting authority, the CSA, warned M6 that its astroturfing attempt contravened articles 20 and 22 from its broadcasting convention: "The company must verify the validity and the sources of information [and] must show honesty and rigor in the presentation and treatment of information" (Conseil supérieur de l'audiovisuel, 2011). A core concern of the circulation and presentation of information in public space is one central to the question of authorship and credibility: astroturfing. In this case, what began as a simple five-minute report on a new digital media technology ended in astroturfing practices being exposed by both digital and traditional media.

This clear case of astroturfing - and how it was uncovered-allows us to observe the interrelationship between astroturfing, digital media use, and the exposure of astroturfing. In France, much as in the United States, audiences are accustomed to marketing and 
public relations. The Freebox/M6 case became a scandal not because it was marketing, but because it was misleading - the family that enjoyed the Freebox was parented by employees of Free. These employees violated what we see as a fundamental factor governing digital communication space: parrhesia, in which the public duty of speakers is to speak the truth, to sincerely believe that truth, and to honestly represent themselves when speaking.

\section{Building a theory of digital parrhesia}

The act of astroturfing may be thought of as manufacturing support for an issue, or attempting to mislead politicians, news media, or citizens about the origins of such support. The use of the term dates at least to 1985, when United States Senator Lloyd Bentsen said, about receiving letters that promoted insurance companies' interests, that, "A fellow from Texas can tell the difference between grass roots and Astroturf. This is generated mail" (qtd. in Sager, 2009). Astroturfing attempts to leech the legitimacy held by grassroots movements, pretending that it is a response from below to governance from above.

Growing access to the tools of digital media production, from email to Web site design to video, have created new communication spaces and communities. Citizens, corporations, and governments all have enhanced abilities to engage in public dialogue about their beliefs, products, and intents - and enhanced abilities to conceal their identities while doing so. Thus, digital communication space introduces new problems for ethos; this realm depends on a proper balance between the ability to create pseudonymous or anonymous online presences, and the public need for transparency in public speech.

Pseudonymity and anonymity surely have their place, for they accommodate truthful comments from individuals who may have valid reasons - from fear of community disapproval to the fear of being "disappeared" by a government - to conceal their identity. Yet, corporations, governments, and their public relations or advertising companies can exploit that same anonymity. What may be legitimately defensive for an individual becomes a public relations tactic for an organization attempting to reduce the risk of advocacy. But if in the digital era, astroturfing is easier than ever, so is learning the true identity of astroturfers, as seen in the Freebox/M6 scandal.

In order to fully understand the role of digital communications in astroturfing, and to develop a method to analyze digital astroturfing, this chapter turns to Foucault's articulation of the ancient Greek concept parrhesia (2001). Commonly translated as "free speech," parrhesia implies that when one has the ability to speak freely, one also has the public duty to speak the truth, to sincerely believe that truth, and to honestly represent oneself when speaking - criteria worth repeating, and to which this chapter will repeatedly return.

This concept was first ported to digital space to make an affirmative argument for the value of the Web site WikiLeaks as a defender of "the agora of information" and a culture

of digital truth-telling (Nayar, 2010). The argument is compelling, but the implications of 
digital parrhesia are both wider and deeper than simply defending WikiLeaks, because, according to Nayar himself, digital cultures generate new communities: "Digital cultures create a new communications culture, which generates a new community, the global civil society ... and the globalisation of conscience. [WikiLeaks] is an embodiment of this new form of communications-leading-to-community, a digital parrhesia" (Nayar, 2010, p. 29). Under this view, new communities emerge whose participants may be judged by whether they adhere to the duties implied by parrhesia. Discourse under parrhesia centers on truth-telling in the service of community. Digital parrhesia is then a necessary component of digital communities, like parrhesia was a necessity in the Greek agora.

Risk balances the duty to speak truthfully in digital parrhesia, and in what Foucault calls the "parrhesiastic game," speakers balance the risk to themselves with the duty to speak the truth. "In parrhesia, the speaker uses his freedom and chooses frankness instead of persuasion, truth instead of falsehood or silence, the risk of death instead of life and security, criticism instead of flattery, and moral duty instead of self-interest and moral apathy" (Foucault, 2001, p. 19-20). If engaging in the parrhesiastic game is courageous, then undermining and exploiting the game is cowardly. Moreover, doing so suspends or negates the rule of the game, and thus suspends - and threatens - the role of the society as a discursive community as well.

Digital parrhesia, then, may be considered a discursive space where a wide range of individuals can engage in truth-telling practices, and a space whose boundaries - the duty to speak the truth, to believe that truth, to honestly represent oneself, all though online media - also provide the beginnings of a critical framework for assessing the credibility of digital texts. Clearly, identifying digital parrhesia as a discursive space and defining the boundaries of that space is useful; it allows us to distinguish between digital actors who seek to reveal the truth, or to conceal it. Getting there, however, requires a clear methodology. And the importance of good methods here cannot be overstated; accusing an author of astroturfing, under digital parrhesia, is tantamount to accusing that author of propagandistic lying.

Digital parrhesia lends itself to semiotic analysis because it identifies different levels of speech. At each level, truth-claims hinge on the medium where the speech occurs, how the speech is distributed, the content of the speech, and the identity of the speaker herself. People who have the ability to speak freely in digital culture also have the obligation to become Bentsen's "fellow from Texas" who can distinguish between grassroots content that emerges from below, and content that is astroturfed down from above.

Distinguishing between the two often is contingent on questions of authorship and discourse. In order to help researchers make this distinction, the next section operationalizes digital parrhesia by integrating the author and the medium into what we call a "techno-semiotic" method of analysis.

\section{Building a techno-semiotic method for digital parrhesia}


The idea that every human construct has different levels of meaning is the basis of semiotics, which itself can be a key that unlocks the structure of communication by revealing patterns of meaning at those levels. Semiotics aims to build builds a coherent approach for analyzing units of meaning. The goal of this chapter is not to solve questions asked by generations of semioticians, from the foundational work (Saussure, 1977; Barthes, 1968; Morris, 1964; Greimas, 1989) to scholars of today (Eco, 1976; Klinkenberg, 2000; Veron, 1988), but rather to operationalize their theoretical work into an easily applied method. The different steps of this method have much in common with the analytical skills used in the humanities and literature studies. And the "techno" part of the techno-semiotic method does not require advanced technical knowledge, but rather awareness that a medium itself is a complex object or condition.

In this way, we propose to understand online statements and the systems in which they evolve. Of the object of research - in the case of this chapter, an advocacy statement that may or may not be astroturfing - four questions must be asked: Where does the statement occur? How is the statement enunciated? What does the statement say? And who said it? These questions correspond to different levels of meaning: the medium, the document, the text, and the discourse. In the techno-semiotic method, the levels, while having separate and identifiable characteristics, are not isolated from each other. Rather, each level plays a role and influences, and is influenced by, the other levels. So each level must be considered through two points of view: looking at properties intrinsic to each specific level of meaning, and looking at how the levels of meaning can and do interact.

First, the practice of semiotics in social science, communication and media studies has shown that exhaustive analyses must not restrict themselves only to content - the technical apparatus of communication must be considered as well. Davallon, for example, suggested that what makes objects of communication research unique is is their "technosemiotic weight" (2004). From the sheet of paper to the PDF document, every document has material features that transform the way we receive and perceive signs, but also influences our research practices and the meanings we give to objects. This is but one aspect of the method-particularly significant at the level of the medium-which is highly influential, but not deterministic, because as Wright suggested, a technical apparatus does not determine communicative processes, which are themselves social, not technological, in nature (1986). Thus, the first step in describing an object is to describe the technical apparatus and the system that produces it. For example, this method always asks whether articles published in The New York Times newspaper, and on nytimes.com, are the same? Is a 1933 speech by United States President Franklin Delano Roosevelt the same when heard on the radio then, and when read in a history textbook today? These are the types of questions that the techno-semiotic method prompts: Where does the statement occur? And how does the medium in which it occurs affect the meaning of the statement? These questions serve to avoid the pitfall of technological determinism, while still insisting that a statement's technological context affects its meaning.

The second step of this method takes us to the level of how a statement is enunciated. This is closely related to the where, or to the medium, but is distinct. Rather than looking at the medium and its systems - the differences between New York Times stories in print 
or online, or the differences between a contemporaneous radio speech and a textbookthe second step turns to the document itself, and the process by which it comes into being. The question of how a statement is enunciated regards how statements become text and how those texts are disseminated. For example, an author rarely publishes handwritten drafts of her work. Instead, she uses word processing software, then sends a copy - sometimes digital, sometimes paper-to her editor, who may send it along for further review by peers and copyeditors, until the document is transformed into a printable version for the printers. Thus, techno-semiotic analysis requires that attention be paid to how documents are produced and distributed, and to how those processes affect and inform the meanings of statements.

Of course, analyses of communication texts are commonly concerned with the content of statements, which is our third level: what the statement says, returning to the classic core question of finding meaning in a text. A news story viewed on YouTube will be different than the same news story viewed during a CNN broadcast. Neither will be understood in exactly the same way, nor will they be understood the same way as the script of the broadcast, or the audio track heard without the video. The medium informs this level, because audiences receive different media differently. Nonetheless, texts - particularly news and digital advocacy - have claims. Those claims must be identified and evaluated, and understood in the context of the previous two levels: to what extent the medium informs those claims, and to what extent how those claims are presented and distributed affects their reception.

The final level of meaning to investigate is the discourse. The analysis of discourse can be as complex as the definition of the term itself. In the techno-semiotic method, research into the content of the message requires gathering some information about the speaker, in order to understand his intentions and purposes. When considering a statement, the question of who said it is then a more global question about the speaker and her relation to the statement. Analysis at the level of discourse is closely and strongly interrelated with the other levels of meaning. Through analysis at the levels of the technics of the medium, of the production and distribution of a text, and of the content of a text, a holistic understanding of a statement and its meaning begins to emerge. To paraphrase and expound upon Marshall McLuhan, if the message is the medium, then we can say that the discourse is the medium: analysis of the medium reveals the space in which the discourse can evolve, can be influenced and transformed, but also for whom it was crafted and to what purpose it was deployed. Meaning is conveyed through discourse and its intent; the techno-semiotic model thus treats the author, in a way, as text.

Traditionally, mass media have served to confer status upon certain speakers - news anchors of major television networks, editors of major newspapers, politicians, and so forth - but in digital communication space, traditional status conferral is dramatically weakened. When discussing matters of public interest in digital communication space, we argue, status is conferred by the honesty of the speaker. Her discourse must fulfill her public parrhesiastic duties, which, again, are: to speak the truth, to sincerely believe that truth, and to honestly represent herself when speaking. As we will see in the examples 
that follow, analyzing the last of these-honest representation - is at the crux of determining whether advocacy speech is astroturfing.

\section{Astroturfing the European Commission: from public consultation to risk manipulation}

In a previous project, Allard-Huver tried to understand how negotiating the concept of risk in the European public sphere transformed advocacy communications (2011). He analyzed the public deliberation from 2002 to 2009 surrounding the 91/414 European Directive regulating pesticides, finding that some public feedback was surprisingly similar, considering letters were supposedly from individuals writing individually. Using the techno-semiotic method, it quickly became clear that an astroturfing attempt was being made within the European legislative process.

During its public consultation for the report Thematic strategy on the sustainable use of pesticides, the European Commission invited pesticide stakeholders to send comments, suggest modifications, put forward reservations and criticize the commission's first publication, Towards a thematic strategy on the sustainable use of pesticides (European Commission, 2009). Some feedback that initially seemed to be from individuals appeared to be a part of a coordinated campaign, when seen through the prism of digital parrhesia and evaluated by the techno-semiotic method. These questions followed from the method:

First, is the European Commission Web site, as a digital public sphere, more subject to astroturfing attempts? The first level of inquiry focuses on the Web site- the media layer - of the European Commission, its functions, and the ways it created a digital public sphere. The site functioned in three ways: it served as a medium that raised public awareness of the problems of pesticides; it built a digital discussion space for public participation in debates about pesticide use; and now, it serves as a public archive for a completed process. Each function makes clear that the Web site is a mediator between different publics. The site, by enunciating the perspectives of European legislators as well as those of other stakeholders, suggests that the rules of parrhesia are at work; in turn, stakeholders, by participating in the process, imply that they accept those rules. But the physical and material distance introduced by Internet communication itself must not be forgotten. On the Web site, distinguishing speakers can be difficult, and one can easily submit false information, or falsify an identity; this admits the possibility of astroturfing into the process. Nevertheless, because the site also plays the role of an archive, the public - and researchers - can investigate the advocacy speech therein, and how parrhesia operates in these debates.

Now, we can look at the third level of meaning: the content of the documents. The principal element of our interrogation is that some of the stakeholder texts are remarkably similar. The text of Birgitt Walz-Tylla is almost the same as the text sent by Carlo Lick, by B. Birk or Joseph Haber. For example, all four letters include this text: "As a scientist who has dedicated most of his career to researching and developing crop protection 
products, I believe there are a number of elements of this strategy that need to be further considered," even Walz-Tylla, a woman who, humorously, has "dedicated most of his career" (emphasis ours) (European Commission, 2009). Here, the content analysis is less the analysis of signs themselves, and more the recognition that the texts are the same. And these seams - like Birgitt Walz-Tylla's apparent claim to manhood, and our ability to quickly compare texts - suggest that these letters are part of a coordinated astroturfing campaign.

So, who then is the speaker? The person who signed these letters? The person or people who wrote the original text, which was then distributed to these four scientists? These questions go directly to the third duty of a speaker in the realm of digital parrhesia: the duty to honestly represent oneself when speaking. These four letters share the same content, but differ slightly in their presentation and the ways in which their authors present themselves publically. All identify themselves as scientists, and some sign their letters with their academic titles, laying a public claim to be experts in their fields. The letters from Birk and Lick clearly state their professional affiliations; both work for BASF, a chemical company with interests in pesticide production. Walz-Tylla and Haber do not provide their professional affiliations. But no matter: a simple Google search reveals that Walz-Tylla is an employee of Bayer CropScience, and Haber is an employee of BASF. Both companies are industry stakeholders.

Thus, what separately seem to be legitimate individual positions of experts are revealed to be the direct participation of industry. This discourse does not arise from the individual concern of scientists, but from what appears to be coordinated industry propaganda. An industrial agent almost certainly wrote the original text, and suggested the campaign to other industrial stakeholders. This actor, in fact, is the true author of the discourse, but stays in the shadows, uses different identities, and ultimately leaves its intention unclear - is the issue one of good science, or good business? In this debate, then, we can say that these four scientists - and whomever wrote their letters for them - do not respect parrhesia. While they may have attempted to exploit the ease of submitting digital feedback, the realm of digital parrhesia also affords the opportunity to uncover their campaign. Therefore, digital parrhesia and the techno-semiotic method reveal what we believe to be a clear case of astroturfing.

\section{Astroturfing Pinellas County, Florida: Secreting Racism}

Astroturfing can be professional, well-styled, and coordinated, as seen in the BASF and BayerCropScience employees submitting letters as individual stakeholders, even though the content thereof is so similar as to suggest a coordinated campaign by industrial stakeholders. Astroturfing can also be petty, but still astroturfing, when a public official spreads individual social biases and political accusations under pseudonyms.

In 2010 and 2011, a commenter on the Web site of the St. Petersburg Times, a daily newspaper in Florida, posted a number of controversial comments under the pseudonym "Reality." The commenter complained about "race pimps" who would "walk around looking like an idiot thug trying to hold your pants up. Whitie isn't to blame for your 
ignorance." Reality also criticized what he saw as St. Petersburg's outsized number of "thug shootings" and "prostitute beatings," and also attacked two Pinellas County commissioners - in one case alleging that a commissioner helped a "developer friend" access funds from the county (DeCamp, 2011b).

A reporter noticed that Reality often ended comments with the phrase "just say'n," a phrase also used by another Pinellas County commissioner named Norm Roche, and he noticed that Reality announced a new Web site in a comment - a Web site registered to Roche. Initially, this might not seem to be a case of astroturfing; after all, Roche was not manufacturing wide support for racism. However, when confronted by a reporter, Roche admitted that he posted both as "Reality" and as "Norm Roche," suggesting a desire to distance his public persona from the views of "Reality." And when critiquing elected officials, including his colleagues, he again used a pseudonym to distance Norm Roche from Reality. Even if the Reality persona was consistent and the author of Reality's comments believed them to be true, that one person operated two personae, whose opinions did not fully align (at least in public), suggested an effort to mislead or misdirect readers of those comments.

The word "secreting" has two meanings: concealing in a hiding place, and forming then emanating a substance. Here, Roche used a pseudonym to conceal the origins of his controversial comments, and possibly to conceal his own controversial views. (It must be noted, however, that Roche has publicly denied being a racist or a homophobe.) At the came time, he used a pseudonym to distribute those controversial comments, and to do so, used a medium that permitted pseudonymous comments and integrated them with news stories. In this case, the journalist who uncovered the relationship between Reality and Norm Roche used something akin to the techno-semiotic method to do so, and we argue that the method works very well to analyze speech in this situation.

As per the method, we first address issues related to the medium. Here, Roche's speech required a news product that offered an online commenting system. Such a system permits an exchange of ideas between readers who participate, and sometimes between readers and journalists, should journalists choose to respond to comments. Immediately, we see that these texts are polysemous-different readers interpret the meaning of news stories differently, including inscribing their own, sometimes divergent, meanings onto those texts. ${ }^{1}$ At the same time, we see how these texts become polyvocal-for readers who do not comment, the news product is the story plus the comment threads. Within such polyvocal texts, voices that threaten the peace of the community can easily be identified. In this case, a reporter identified outlandish claims by a commenter. These claims could not exist without the newspaper offering a comment thread, which offering, in turn, introduced polyvocality into its news product. The digital text therefore has the ability to reveal through its medium the plurality of voices that create and recreate new texts.

Second, we address questions related to how the speech is distributed. In the case of these comment threads, reader comments are attached to the end of a news story. Online, the

\footnotetext{
${ }^{1}$ A phenomenon readily seen in comment threads following all political stories, for example.
} 
St. Petersburg Times publishes stories along with the comments; at the end of the story, the reader must click a link reading "Join the discussion: Click to view comments, add yours." While other content exists on the page, ranging from advertisements to copyright information to links to other news stories, only links to the comments, or links that help readers repurpose the story by sharing or printing it, are directly connected to the story itself. When commenting, a reader becomes a reader-author; when sharing a story by email or on a blog, the reader becomes a reader-publisher. In both cases, a participating reader implicates herself in a case of digital parrhesia, especially because she must agree to "Comment policy and guidelines" which include, among others, the requirement that "Your comments must be truthful. You may not impersonate another user or a tampabay.com staff member by choosing a similar screen name. You must disclose conflicts of interest" (Tampabay.com, 2012). Finally, other commenters indicated a parrhesiastic situation, because they implicitly interrogated and summoned the criteria of digital parrhesia. On the story revealing that Reality was Norm Roche, many of the 137 comments debated whether the publication had violated its own promises of privacy to its commenters, whether the reporter had used honest techniques to uncover this story, and whether a commenter should take responsibility for his comments by posting them under his real name.

Next, we address questions about the content of the speech. The comments by Reality were often incendiary, supporting biases of some commenters and provoking outrage among others. Reader comments, in fact, operate as at least three different texts. First, comments exist in relation to the news story-expanding it, criticizing it, and opining on it. Second, comments exist in relation to other comments; they respond to previous comments while anticipating future ones. Third, comments exist as part of a complete news product, one that includes news story and all comments, that is served to noncommenting readers. The digital text is at the crossroads of the journalist's production of meaning and the public's reception and sometimes re-appropriation of it. The reporter who revealed Reality as Roche did so by understanding the first two content interrelationships - by identifying commonalities between supposedly different voices, and ultimately revealing them to be the same.

Finally, we consider the speaker himself. All four of the levels of the techno-semiotic method interrelate, but questions of discourse are perhaps the most pervasive of all. Above, we have seen how online commenting systems promote polyvocal texts, and thus create opportunities for deviant speech. We also have seen that by posting comments, readers become reader-authors, and in doing so, implicate themselves in a parrhesiastic system. Further, even the most cursory look at the content of reader comments reveals that understanding their intertextual and multitextual nature allows us to see the different ways in which content may be deployed. Discourse, then, is overlaid on all of these. The question of who is commenting and why may be the fundamental question of digital ethos in online texts such as these. In this case, once the reporter marshaled his evidence and asked Roche if he was Reality, Roche admitted that his reasons for concealing his identity (at least part of the time) were entirely discursive. He told the reporter, "A lot of it can be rhetoric and rants. Unfortunately it's part of our communication base now, and you have to be part of it, you have to track it" (Decamp, 2011a). 
Thus, we see how a reporter used a process much like the techno-semiotic method to break a news story about a politician who concealed his identity while making possibly racist comments about his constituents. And we also see how different layers of meaning generated through the medium, its distribution, its content, and its author are all available to analyze the credibility of online speech.

\section{Conclusion: Digital parrhesia and digital communication texts}

Clearly, an application of digital parrhesia has the potential to evaluate and assess astroturfing that is spread through digital media. Under the parrhesia model, truth-claims are reviewed in three ways: whether they are true, whether the speaker believes that they are true, and whether the speaker is honestly representing herself. Again, parrhesia accommodates pseudonymous and anonymous speech because honesty does not require mapping a name onto a real speaker, but rather requires that the speaker honestly believes in and argues for her truth claims. The techno-semiotic method accounts for this, but it also has wider implications.

As Nayar suggested, digital communication constitutes new communities (2010). This is not a new phenomenon - we have seen it before in the old bulletin board systems and chat rooms, and we see it today in online communities ranging from 4chan to Facebook groups. These communities, as all communities do, develop their own behavioral norms and mores. These norms help define the discursive space of digital parrhesia; the risks to a speaker for violating those norms - in the digital space, ranging from chastisement to banishment - help determine when and how the speaker will fulfill her duties to speak the truth, to believe that her truth-claim is indeed true, and to honestly represent herself and her belief. For astroturfers, the risk is that a secret propaganda campaign will be revealed, with consequences ranging from public shame to criminal liability.

To operationalize digital parrhesia - to make it useable not only for academic critics, but to make a model that can be used to consider digital communication more broadly - we have integrated the medium and the speaker into our techno-semiotic method. Doing so solves a major problem with the sender-receiver model of communications, which manages to persist even when it is not appropriate. Under a sender-receiver model, texts can be recognized as univocal and polysemous - that is, readers can negotiate their own meanings with texts, even meanings that run counter to the preferred reading of a univocal author. But when texts become polyvocal, and when the medium itself-for example, an online news story with comments - creates polyvocality, the sender-receiver model falters.

Polyvocality in digital media permits the exposure of astroturfers. In this chapter alone, we have seen fans of a product, a scholar (Allard-Huver, 2011) and a journalist (DeCamp, 2011a; DeCamp, 2011b) all use observations made through or use techniques reliant upon digital media to expose astroturfing that, itself, was at least partially executed through digital media. This suggests that polyvocal media and polyvocal texts, 
when functioning in a parrhesiastic way (that is to say, when discussing community issues in ways that hinge on acts of truth-telling), are especially appropriate subjects for the techno-semiotic analysis outlined in this chapter.

The astroturfing cases outlined here - audience members uncovering that a popular science television show became a propaganda and advertising piece in France; the distribution of the PDF of a European Commission report compiling the feedback of stakeholders regarding pesticide use; and a journalist revealing that an elected official clandestinely stoked the fires of racism in Florida - suggest the versatility of both digital parrhesia as a theory and the techno-semiotic method as a method. 


\section{REFERENCES}

Allard-Huver, F. (2011). Transformation and circulation of the notion of "risk" in the European Commission. Unpublished Master Thesis, University of ParisSorbonne, Paris.

Barthes, R. (1968). Elements of semiology. New York: Hill and Wang.

Conseil supérieur de l'audiovisuel (2011, October 18). Convention de la chaîne M6. Retrieved February 12, 2012, from http://www.csa.fr/Espacejuridique/Conventions-des-editeurs/Convention-de-la-chaine-M6.

Davallon, J. (2004). Objet concret, objet scientifique, objet de recherche. HERMES, 38, $30-37$.

DeCamp, D. (2011a, November 17). Pinellas county commissioner Norm Roche has alter ego for online comments. St. Petersburg Times, retrieved January 22, 2012, from http://www.tampabay.com/news/localgovernment/article1202065.ece.

DeCamp, D. (2011b, November 18). Norm Roche's anonymous online snark strains city, county relations. St. Petersburg Times, retrieved January 22, 2012, from http://www.tampabay.com/news/politics/local/norm-roches-anonymous-onlinesnark-strains-city-county-relations/1202287.

Eco, U. (1976). A theory of semiotics. Bloomington: Indiania University Press.

European Commission (2009). Towards a thematic strategy on the sustainable use of pesticides. European Commission, Environment.

Foucault, M. (2001). Fearless speech. Los Angeles: Semiotext(e).

Freenews (2011a, May 17). La Freebox à l'honneur dans E=M6 (MàJ). Retrieved February 12, 2012, from http://www.freenews.fr/spip.php?article8300.

Freenews (2011b, October 11). Reportage bidon sur la Freebox dans E=M6: intervention du CSA. Retrieved February 12, 2012, from http://www.freenews.fr/spip.php?article9131.

Greimas, J. (1989). The social sciences. A semiotic view. Minneapolis: University of Minnesota Press.

Klinkenberg, J-M. (2000). Précis de sémiotique générale. Paris: Seuil.

McLuhan, M. (1994). Understanding media: The extensions of man.

Morris, C. W. (1964). Signification and significance: A study of the relations of signs 
and values. Cambridge: MIT Press.

Nayar, P.K. (2010, December 25). Wikileaks, the new information cultures and digital parrhesia. Economic and Political Weekly (45)52, 27-30.

Sager, R. (2009, August 18). Keep off the astroturf. [Electronic version]. The New York Times. Retreived January 22, 2012, from http://www.nytimes.com/2009/08/19/opinion/19sager.html.

Saussure, F. (1977). Course in general linguistics. Glasgow: Fontana/Collins.

Tampabay.com (2012). Comments policy. Retrieved January 22, 2012, from http://www.tampabay.com/universal/comment_guidelines.shtml.

Veron, E. (1988). La sémiosis sociale. Fragments d'une theorie de la discursivité, París: Presses Universitaires de Vincennes.

Wright, C. R. (1986). Mass communication: A sociological perspective. New York: Random House. 